(1)

CrossMark

\title{
Managing the supportive care needs of those affected by COVID-19
}

\author{
Sabrina Bajwah (10 ${ }^{1}$, Andrew Wilcock (10) ${ }^{2}$, Richard Towers ${ }^{3}$, Massimo Costantini ${ }^{4}$, \\ Claudia Bausewein ${ }^{5}$, Steffen T. Simon ${ }^{6}$, Elisabeth Bendstrup ${ }^{7}$, Wendy Prentice ${ }^{3}$, \\ Miriam J. Johnson ${ }^{8}$, David C. Currow ${ }^{9}$, Michael Kreuter ${ }^{10}$, Athol U. Wells ${ }^{11}$, \\ Surinder S. Birring ${ }^{12}$, Polly Edmonds ${ }^{3}$ and Irene J. Higginson (1) ${ }^{1}$
}

Affiliations: 'Cicely Saunders Institute, Dept of Palliative Care Policy and Rehabilitation, King's College London, London, UK. ${ }^{2}$ University of Nottingham, Nottingham, UK. ${ }^{3}$ Dept of Palliative Care, King's College Hospital, London, UK. ${ }^{4}$ Azienda USL-IRCCS di Reggio Emilia, Reggio Emilia, Italy. ${ }^{5}$ Dept of Palliative Medicine, LMU Klinikum, Ludwig-Maximilians-University, Munich, Germany. ${ }^{6}$ Dept of Palliative Medicine and Center for Integrated Oncology, University of Cologne, Faculty of Medicine and University Hospital, Cologne, Germany. ${ }^{7}$ Centre for Rare Lung Diseases, Dept of Respiratory Diseases and Allergy, Aarhus University Hospital, Aarhus, Denmark. ${ }^{8}$ Wolfson Palliative Care Research Centre, Hull York Medical School, University of Hull, Hull, UK. ${ }^{9}$ IMPACCT, Faculty of Health, University of Technology Sydney, Ultimo, Australia. ${ }^{10}$ Center for Interstitial and Rare Lung Diseases, Thoraxklinik, University of Heidelberg, German Center for Lung Research, Heidelberg, Germany. ${ }^{11}$ Royal Brompton Hospital, London, UK. ${ }^{12}$ Centre for Human and Applied Physiological Sciences, School of Basic and Medical Biosciences, Faculty of Life Sciences and Medicine, King's College London, London, UK.

Correspondence: Sabrina Bajwah, Cicely Saunders Institute, Dept of Palliative Care Policy and Rehabilitation, King's College London, Bessemer Road, London SE5 9PJ, UK. Email: sabrina.bajwahakcl.ac.uk

@ERSpublications

For patients with COVID-19, there is a moral obligation to provide good supportive care to prevent avoidable suffering. This article provides a succinct informative overview, clinical guidance and information sheets for both patients and families. https://bit.ly/2UPFsOj

Cite this article as: Bajwah S, Wilcock A, Towers R, et al. Managing the supportive care needs of those affected by COVID-19. Eur Respir J 2020; 55: 2000815 [https://doi.org/10.1183/13993003.00815-2020].

\section{Introduction}

Globally, the number of people affected by coronavirus disease 2019 (COVID-19) is rapidly increasing. In most $(>80 \%)$, the illness is relatively mild and can be self-managed out of hospital. However, for about $20 \%$, the illness causes respiratory compromise severe enough to require hospital admission [1]. Patients with severe and critical disease need full active treatment. This may include oxygen for hypoxaemia and ventilatory support, along with optimal management of complications, e.g. super-imposed bacterial infection, and any underlying comorbidities, e.g. COPD or congestive heart failure. To date, no antiviral agent has shown to be effective in treating the disease [2].

Patients with severe disease not considered suitable for escalation to intensive care, i.e. those who are frail or have multiple comorbidities, are at very high risk of dying, with an estimated death rate of $15-22 \%$ [3, 4]. We have a moral obligation to provide good symptom control to prevent avoidable suffering. Thus, comprehensive care of the patient with COVID-19 requires identification of patients at increased risk of dying, who would benefit from a parallel approach to management. This encompasses optimal symptom management for those with severe disease but who will survive, and expert symptom management and end of life care for those that are deteriorating and in their last days or hours of life. The aim of this

This article has supplementary material available from erj.ersjournals.com

Received: 23 March 2020 | Accepted after revision: 5 April 2020

Copyright $\odot$ ERS 2020. This article is open access and distributed under the terms of the Creative Commons Attribution Non-Commercial Licence 4.0. 
editorial is to provide a succinct informative overview to guide respiratory healthcare professionals on the frontline.

\section{Symptom relief}

The most common symptoms are breathlessness, cough and fever.

\section{Breathlessness}

Breathlessness affects between 5\% and 65\% of patients with COVID-19 [5-9].

The highest incidence will be in those with severe disease and is expected in those actively dying. The primary driver of breathlessness is the viral lung infection causing an interstitial pneumonia with a reduction in lung diffusing capacity; in some patients this evolves to acute respiratory distress syndrome (ARDS). The experience of breathlessness is also influenced by emotional, environmental, cultural and social factors, and optimal management requires a holistic approach. These include non-pharmacological and pharmacological approaches. Non-pharmacological approaches include breathing techniques [10]. Although an electric hand-held fan directed at the face is helpful in other settings [10, 11], this is not recommended in COVID-19 because of the theoretical infection control risk of spreading infected droplets. As an alternative, use of facial cooling with wet wipes (binning after each use, as for tissues) can be tried.

Pharmacological approaches are the mainstay of management for patients with severe disease who are likely to have rapidly worsening breathlessness at rest. Morphine is the opioid of choice [12, 13]. However, alternative strong opioids can be used. Short-acting oral opioids, given as required, may suffice when breathlessness is mild. However, in severe disease or at the end of life, continuous infusions of parenteral opioids are preferable, maximising symptom management, whilst reducing nurse and community staff time, use of resource-limited protective equipment and exposure. Use of the parenteral route is also preferred for speed of onset of action and ability to rapidly titrate doses. If there is distressing breathlessness at rest, opioids should be combined with an anxiolytic sedative, e.g. midazolam (table 1). Rapid titration of benzodiazepines may be needed. The primary role of oxygen is to correct hypoxaemia. There is a suggestion it may help breathlessness in severe hypoxaemia [14], but not when mild or absent [15]. In a comatose/unresponsive dying patient, oxygen can be titrated down with goal of discontinuation, while concurrently managing symptoms of breathlessness [16].

\section{Cough}

Cough affects between $70 \%$ and $80 \%$ of patients with COVID-19 [5-9].

Potential mechanisms in viral respiratory infection and ARDS include inflammation, epithelial damage, mucus impaction and neuro-modulatory changes (heightened cough reflex sensitivity) [17]. Evidence for effective management of acute cough is limited [18, 19]. Adequate hydration and regular small sips of water may help [20]. However, because of the likely concurrent need for breathlessness management, strong opioids are likely to be more pragmatic in practice. High-level evidence is limited [21, 22], but relatively low doses of long-acting oral morphine (5-10 mg twice daily) are helpful in refractory chronic cough (table 1) [21]. Although these patients do not have chronic cough, opioids may be helpful in reducing cough alongside treatment for breathlessness [22].

\section{Delirium}

Delirium is common in medical illness and almost universal in the last days or hours of life. Non-pharmacological management includes regular orientation, avoiding constipation, treating pain, maintaining oxygenation and avoiding urinary retention [23]. When ineffective and where the delirium is causing significant distress, pharmacological therapy with an antipsychotic (such as haloperidol) should be considered; in the context of severe breathlessness and at the end of life, a sedative anxiolytic such as levomepromazine or midazolam should be used (table 1) to allow rapid titration if needed.

\section{Anxiety}

Anxiety secondary to breathlessness, social isolation and fear is likely to be present to some degree in all patients with COVID-19. Severely ill patients may be particularly distressed, due to the looming possibility that their situation may rapidly worsen and that they may die, potentially compounded by the loss of support from their families, who are not allowed to visit, and receiving care from health professionals in personal protective equipment. Non-pharmacological methods such as relaxation therapy and breathing exercises are effective in mild anxiety but if patients are significantly anxious or have severe disease, the focus should be on pharmacological management. For severe disease and if people are actively dying, benzodiazepines are likely to be most effective [24]. Optimal relief may necessitate increasing depths of sedation rapidly in the last days and hours of life, particularly when associated with severe breathlessness (table 1). 
TABLE 1 Example clinical guidelines for the management of the severe/dying coronavirus disease 2019 (COVID-19) patient

\begin{tabular}{|c|c|c|}
\hline Symptom/need & Clinical indication & Recommendation \\
\hline $\begin{array}{l}\text { Distressing } \\
\text { breathlessness at rest }\end{array}$ & & $\begin{array}{l}\text { - Stat dose morphine } 2.5 \mathrm{mg} \mathrm{SC} / \mathrm{IV}+\text { midazolam } 2.5 \mathrm{mg} \mathrm{SC} / \mathrm{IV} \text { (reduce both to } 1.25 \mathrm{mg} \text { if } \\
\text { eGFR }<30 \text { or elderly) } \\
\text { If continuous infusion is available } \\
\text { - Morphine } 10 \mathrm{mg}+\text { midazolam } 10 \mathrm{mg} \text { CSCI/IV over } 24 \mathrm{~h} \text { OR morphine } 5 \mathrm{mg}+ \\
\text { midazolam } 5 \mathrm{mg} \mathrm{CSCI/IV} \mathrm{over} 24 \mathrm{~h} \text { lif eGFR <30 or in the elderly) } \\
\text { - In addition, prescribe morphine } 2.5 \mathrm{mg}+\text { midazolam } 2.5 \mathrm{mg} \mathrm{SC/IV} \mathrm{p.r.n.} 4 \text { hourly } \\
\text { (1.25 mg for both if eGFR <30 or in the elderly) } \\
\text { If continuous infusion is not available } \\
\text { - Morphine } 2.5 \mathrm{mg} \mathrm{SC} / \mathrm{IV}+\text { midazolam } 2.5 \mathrm{mg} \mathrm{SC/IV} 4 \text { hourly }(1.25 \mathrm{mg} \text { for both if eGFR } \\
<30 \text { or in the elderly) } \\
\text { - In addition, prescribe morphine } 2.5 \mathrm{mg} \mathrm{SC} / \mathrm{IV}+\text { midazolam } 2.5 \mathrm{mg} \text { SC/IV p.r.n. } 4 \\
\text { hourly (1.25 mg for both if eGFR<30 or in the elderly) } \\
\text { Monitor patients receiving opioids for undesirable effects, particularly nausea and } \\
\text { vomiting, and constipation. Depending on individual circumstances, prescribe a regular } \\
\text { or p.r.n anti-emetic and a regular laxative. }\end{array}$ \\
\hline
\end{tabular}

$\begin{array}{ll}\text { Anxiety } & \text { Mild } \\ & \text { Moderate/severe }\end{array}$

Cough

Fever

Delirium

Mild confusion

Delirium with distress

Delirium/agitation at end of life
- Relaxation techniques and breathing exercises

- Midazolam $2.5 \mathrm{mg}$ SC/IV p.r.n. (1.25 mg for both if eGFR <30 or in the elderly) If needed regularly, consider a CSCI/IV infusion (starting dose midazolam $10 \mathrm{mg}$ per $24 \mathrm{~h}$; reduce to $5 \mathrm{mg}$ if eGFR<30 or elderly).

If continuous infusion is available

- Morphine $10 \mathrm{mg} \mathrm{CSCI/IV} \mathrm{over} 24 \mathrm{~h}$ (5 mg CSCI/IV if eGFR <30 or elderly)

If continuous infusion is not available

- Morphine $2.5 \mathrm{mg} \mathrm{SC/IV} 4$ hourly (1.25 mg for both if eGFR $<30$ or in the elderly) Monitor patients receiving opioids for undesirable effects, particularly nausea and vomiting, and constipation. Depending on individual circumstances, prescribe a regular or p.r.n. anti-emetic and a regular laxative.

- Paracetamol $1 \mathrm{~g}$ QDS PO/IV lavoid NSAIDs unless end of life)

- Orientation to time and place

- Orientation to time and place, if ineffective haloperidol 1-10 mg SC/IV in 1-3 divided doses over $24 \mathrm{~h}$; maximum $10 \mathrm{mg}$ per day (halve all doses in elderly; maximum $5 \mathrm{mg}$ per dayl

- Stat dose levomepromazine $25 \mathrm{mg} \mathrm{SC/IV} \mathrm{or} \mathrm{midazolam} 5 \mathrm{mg}$ (reduce to levomepromazine $12.5 \mathrm{mg}$ and midazolam $2.5 \mathrm{mg}$ if eGFR $<30$ or elderly) If needed regularly, consider CSCI/IV infusion leither levomepromazine $50 \mathrm{mg}$ or midazolam $15 \mathrm{mg}$ per $24 \mathrm{~h}$; reduce to levomepromazine $25 \mathrm{mg}$ or midazolam $7.5 \mathrm{mg}$ lif eGFR $<20$ or elderly).

Note: may need to titrate rapidly if ongoing agitation. When on both opioid and sedative: titrate the sedative up for terminal delirium NOT the opioid.

Communication Patients

Family
- "I understand that this is an emotional time, anyone would be scared/anxious ... it is normal to be worried and scared."

- "We do not think recovery from this illness is possible and [you/they] may die over the next [few hours / days / short weeks]."

- "I am very sorry that you cannot have your loved ones around you, but as you can see, you are here with us, you are not alone, we will stay with you."

- "What concerns you the most?" "It's understandable you feel this way / This must be really hard for you / It is upsetting." "Who is around to support you?" "Is there something we can do to help?"

- "We are concerned about the condition of your [relative] and think that they are sick enough to die'."

CSCI: continuous subcutaneous infusion; SC: subcutaneous; IV: intravenous; PO: per oral; BD: twice daily; GFR: glomerular filtration rate; NSAID: non-steroidal anti-inflammatory drugs. Further information/resources available at: https://www.vitaltalk.org/guides/covid-19-communicationskills/, SIGN delirium guidance https://www.sign.ac.uk/sign-157-delirium 


\section{Information for patients admitted to hospital with COVID-19}

COVID-19 can cause minor to serious illness.

You have been admitted to hospital with COVID-19 so that we can monitor your breathing. Your breathing may need to be supported with oxygen and sometimes with a ventilator (artificial breathing). We also want to help with any symptoms you may have.

This leaflet will explain what treatment you may receive, and what support will be available.

\section{What treatment will I receive?}

Alongside active measures to treat the disease, it is important that we reduce the distress that you may experience. This is done through treating your symptoms:

- Breathlessness can be improved by keeping as calm and relaxed as possible, but if your breathlessness gets worse, we will use medication to help with this. Morphine is the most common medicine used. Although usually given for pain, morphine can be used safely to relieve the feeling of breathlessness.

- Cough can also be relieved by morphine.

- Anxiety can be common; medicines used to help with this symptom include lorazepam and midazolam.

- Restlessness can occur if you develop a fever and this can be controlled using paracetamol.

All medicines will be given regularly and when you need them. If you become unable to swallow the medicine, it can be given as an injection either through a vein or under the skin.

In the most serious cases, COVID-19 can severely affect the lungs, stopping them from working normally. A ventilator may be used to move air into and out of the lungs to help you breathe. You may need to be on a ventilator for several days until your lungs are able to work properly again.

\section{Can I decide how I am treated?}

You should talk to the doctors about what is important to you. You may have preferences about how and when certain actions should be taken. For example, when to start ventilation or whether to restart the heart if it stops. The doctors will take your views into consideration together with your medical condition. Difficult decisions about your medical care may need to be made quickly if you become unwell so it is important that you let the medical team know what you want them to do. If you are unsure, please discuss this with a member of the medical team.

\section{How can I communicate with those important to me?}

There are strict isolation rules in place both outside and inside the hospital, which means that you may not be allowed visitors. Any visitors will have to wear personal protective equipment (otherwise known as PPE - face masks etc.). Where possible, ward staff will try to help you communicate with people important to you by telephone or video calls. Please let the ward staff know if you are happy for them to share information in this way and if there are specific people you wish to be kept informed.

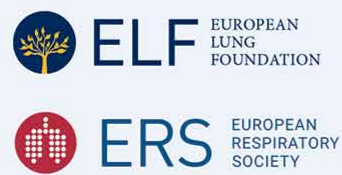

This information leaflet was compiled by Dr Sabrina Bajwah (Cicely Saunders Institute, King's College London) with extensive input from co-authors and patient/carer groups to accompany the ERJ editorial "Managing the supportive care needs of those affected with COVID-19". Please cite this editorial as follows:

Bajwah S, Wilcock A, Towers R, Costantini M, Bausewein C, Simon ST, Bendstrup E, Prentice W, Johnson MJ, Currow DC, Kreuter M, Wells AU, Birring SS, Edmonds P, Higginson IJ (2020). Managing the supportive care needs of those affected by COVID-19. ERJ: doi (10.1183/13993003.00815-2020)

Produced in April 2020

www.europeanlung.org

FIGURE 1 Example information sheet for coronavirus disease 2019 (COVID-19) patients admitted to hospital.

Psychological support

Families of patients with COVID-19 face a significant psychological burden that is often magnified by family members themselves being in isolation or under financial strain. Often, more than one member of the same family may be infected and in hospital. Visiting is likely to also be limited/prohibited. There may 


\section{Information for family/friends of those admitted to hospital with COVID-19}

COVID-19 can cause minor to serious illness.

Your family member/friend has been admitted to hospital with COVID-19 so that we can monitor their breathing. Their breathing may need to be supported with oxygen and sometimes with a ventilator (artificial breathing). We will also help with any symptoms they may have.

This leaflet will explain what treatment they may receive, and what support will be available to them and you.

\section{What treatment will they receive?}

Alongside active measures to treat the disease, it is important that we reduce the distress that they may experience. This is done through treating symptoms:

- Breathlessness can be improved by keeping as calm and relaxed as possible, but if breathlessness gets worse, we will use medication to help with this. Morphine is the most common medicine used. Although usually given for pain, morphine can be used safely to relieve the feeling of breathlessness.

- Cough can also be relieved by morphine.

- Anxiety can be common; medicines used to help with this symptom include lorazepam and midazolam.

- Restlessness can occur if a fever develops and this can be controlled using paracetamol.

All medicines will be given regularly and when needed. Medicines can be given as an injection either through a vein or under the skin if necessary.

In the most serious cases, COVID-19 can severely affect the lungs, stopping them from working normally. A ventilator may be used to move air into and out of the lungs to help with breathing. A ventilator may be used for several days until the lungs are able to work properly again.

\section{Making decisions}

Difficult decisions about the care your family member/friend receives may need to be made rapidly by the medical teams. For example, when to start ventilation or whether to restart the heart if it stops. Please let the medical team know whether you have had these discussions with your family member/friend already and what they said. If you are unsure, then please discuss with one of the medical team. Many of the conversations with the doctors and nurses will have to take place on the telephone and we recognise that this will be difficult. Please make sure we have your correct contact details and let the ward staff know if you wish to be kept informed.

\section{How can I communicate with them?}

There are strict isolation rules in place both outside and inside the hospital, which means that you may not be allowed to visit. If visiting the hospital, you will have to wear personal protective equipment (otherwise known as PPE - face masks etc.). Where possible, ward staff will help you communicate by telephone or video calls.

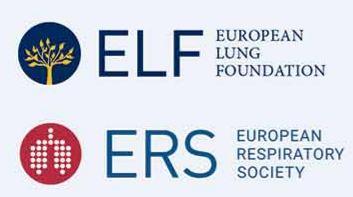

This information leaflet was compiled by Dr Sabrina Bajwah (Cicely Saunders Institute, King's College London) with extensive input from co-authors and patient/carer groups to accompany the ERJ editorial "Managing the supportive care needs of those affected with COVID-19". Please cite this editorial as follows:

Bajwah S, Wilcock A, Towers R, Costantini M, Bausewein C, Simon ST, Bendstrup E, Prentice W, Johnson MJ, Currow DC, Kreuter M, Wells AU, Birring SS, Edmonds P, Higginson IJ (2020). Managing the supportive care needs of those affected by COVID-19. ERJ: doi (10.1183/13993003.00815-2020)

Produced in April 2020

FIGURE 2 Example information sheet for families/friends of coronavirus disease 2019 (COVID-19) patients admitted to hospital.

also be guilt over possibly transmitting the infection to their loved one. The quality of the dying experience and lack of preparation for the death are both predictors of complicated grief. Health professionals should communicate with families regularly and where possible facilitate communication 
between patients and their families utilising virtual technology [25]. Information leaflets should be provided for both patients and family members. If family members are unable to visit, leaflets should be emailed where possible. Figures 1 and 2 provide example leaflets that can be used and are also provided as supplementary files in downloadable and editable document format. Translations are available at https:// www.europeanlung.org/en/news-and-events/news/covid-19-factsheets

\section{Information needs and parallel planning}

In patients with severe disease, there is a need for parallel planning: hoping for the best but preparing for the worst. Therefore, there is an urgent need for early and honest discussions at the time of hospitalisation/diagnosis of COVID-19 for those with a high risk of severe illness and death. Health professionals should focus on advance care planning with open and honest conversations as to what is important to the individual, to inform treatment escalation planning, including resuscitation status, should they deteriorate.

Health professionals should acknowledge the distress of this complex and unique situation, and be compassionate, respectful and empathic. We must explain that active resuscitative care and symptom management do not need to be mutually exclusive, where resources allow. The focus of care should be iterative, adapting to worsening clinical status or patient expressed altered goals of care. Importantly, healthcare professionals need to be proactive in the provision of information and ensure that if there is a significant possibility that the patient will die, that this is addressed with both the patient and family (table 1).

\section{Spiritual care}

The importance of spirituality in coping with uncertainty, severe disease and at the end of life is recognised [26]. Spiritual wellbeing offers some protection against end of life despair in those for whom death is imminent [26]. Hospital chaplains provide spiritual care that helps patients facing serious illness better cope with their symptoms and prognosis. Most hospitals around the world will have chaplains/ representatives from all faiths in the chaplaincy office. The family of the patient or the dying patient may want to see speak to someone about their impending death. Chaplain interventions, whether or not religious, focused on comforting the patient and improving his or her well-being in the context of both his or her spiritual pain and critical illness should be explored with all patients and family [27]. It is important that the spiritual care needs of those who are not represented by chaplaincy available or who are not religious, should also be addressed.

\section{Conclusion}

COVID-19 patients with severe disease/at the end of life have an equal right to care. Receiving adequate symptom control is a basic human right and we have a fundamental duty to relieve suffering and provide the best care with the available resources regardless of the chances of survival.

Acknowledgements: Thank you to all the patients and members of the public at the European Lung Foundation and Cicely Saunders Institute as well as Howard Almond (Action for Pulmonary Fibrosis) and Sarah Dix for their valuable contributions to drafting the information leaflets.

Conflict of interest: None declared.

Support statement: This study/project is supported by the National Institute for Health Research (NIHR) Applied Research Collaboration South London (NIHR ARC South London) at King's College Hospital NHS Foundation Trust. The views expressed are those of the author(s) and not necessarily those of the NIHR or the Department of Health and Social Care.

\section{References}

1 WHO-China Joint Mission. Report of the WHO-China Joint Mission on Coronavirus Disease 2019 (COVID-19) 2020. www.who.int/docs/default-source/coronaviruse/who-china-joint-mission-on-covid-19-final-report.pdf Date last accessed: 17 March, 2020.

2 Rubin EJ, Baden LR, Morrissey S. Audio interview: new research on possible treatments for Covid-19. $N$ Engl J Med 2020; 382: e30.

3 Zhou F, Yu T, Du R, et al. Clinical course and risk factors for mortality of adult inpatients with COVID-19 in Wuhan, China: a retrospective cohort study. Lancet 2020; 395: 1054-1062.

4 Guan W-J, Liang W-H, Zhao Y, et al. Comorbidity and its impact on 1,590 patients with COVID-19 in China: a nationwide analysis. medRxiv 2020; preprint. [https://doi.org/10.1101/2020.02.25.20027664].

5 Guan W-J, Ni Z-Y, Hu Y, et al. Clinical characteristics of coronavirus disease 2019 in China. N Engl J Med 2020; in press. [https://doi.org/10.1056/NEJMoa2002032].

6 Yang X, Yu Y, Xu J, et al. Clinical course and outcomes of critically ill patients with SARS-CoV-2 pneumonia in Wuhan, China: a single-centered, retrospective, observational study. Lancet Respir Med 2020; in press. [https://doi. org/10.1016/S2213-2600(20)30079-5]. 
7 Xu X-W, Wu X-X, Jiang X-G, et al. Clinical findings in a group of patients infected with the 2019 novel coronavirus (SARS-Cov-2) outside of Wuhan, China: retrospective case series. BMJ 2020; 368: m606.

8 Wang L, Gao Y-H, Zhang G-J. The clinical dynamics of 18 cases of COVID-19 outside of Wuhan, China. Eur Respir J 2020; in press. [https://doi.org/10.1183/13993003.00398-2020].

9 Zhang S, Li H, Huang S, et al. High-resolution CT features of 17 cases of corona virus disease 2019 in Sichuan province, China. Eur Respir J 2020; in press. [https://doi.org/10.1183/13993003.00334-2020].

10 Higginson IJ, Bausewein C, Reilly CC, et al. An integrated palliative and respiratory care service for patients with advanced disease and refractory breathlessness: a randomised controlled trial. Lancet Respir Med 2014; 2: 979-987.

11 Gysels M, Reilly CC, Jolley CJ, et al. How does a new breathlessness support service affect patients? Eur Respir J 2015; 46: 1515-1518.

12 Ekström M, Nilsson F, Abernethy AA, et al. Effects of opioids on breathlessness and exercise capacity in chronic obstructive pulmonary disease. A systematic review. Ann Am Thorac Soc 2015; 12: 1079-1092.

13 Ekström M, Bajwah S, Bland JM, et al. One evidence base; three stories: do opioids relieve chronic breathlessness? Thorax 2018; 73: 88-90.

14 Bruera E, de Stoutz N, Velasco-Leiva A, et al. Effects of oxygen on dyspnoea in hypoxaemic terminal-cancer patients. Lancet 1993; 342: 13-14.

15 Abernethy AP, McDonald CF, Frith PA, et al. Effect of palliative oxygen versus room air in relief of breathlessness in patients with refractory dyspnoea: a double-blind, randomised controlled trial. Lancet 2010; 376: 784-793.

16 Campbell ML, Yarandi H, Dove-Medows E. Oxygen is nonbeneficial for most patients who are near death. J Pain Symptom Manage 2013; 45: 517-523.

17 Atkinson SK, Sadofsky LR, Morice AH. How does rhinovirus cause the common cold cough? BMJ Open Respir Res 2016; 3: e000118.

18 Malesker MA, Callahan-Lyon P, Ireland B, et al. Pharmacologic and nonpharmacologic treatment for acute cough associated with the common cold: CHEST Expert Panel Report. Chest 2017; 152: 1021-1037.

19 Hill AT, Gold PM, El Solh AA, et al. Adult outpatients with acute cough due to suspected pneumonia or influenza: CHEST Guideline and Expert Panel Report. Chest 2019; 155: 155-167.

20 Mitchell SAC, Garrod R, Clark L, et al. Physiotherapy, and speech and language therapy intervention for patients with refractory chronic cough: a multicentre randomised control trial. Thorax 2017; 72: 129-136.

21 Fuller RW, Karlsson JA, Choudry NB, et al. Effect of inhaled and systemic opiates on responses to inhaled capsaicin in humans. J Appl Physiol 1988; 65: 1125-1130.

22 Morice AH, Millqvist E, Bieksiene K, et al. ERS guidelines on the diagnosis and treatment of chronic cough in adults and children. Eur Respir J 2020; 55: 1901136.

23 Health Improvement Scotland. SIGN. Risk Reduction and Management of Delirium, 2019. www.sign.ac.uk/ sign-157-delirium Last accessed March 2020.

24 Practice guideline for the treatment of patients with panic disorder. Work Group on Panic Disorder. American Psychiatric Association. Am J Psychiatry 1998; 155: 5 Suppl., 1-34.

25 Lobb EA, Kristjanson LJ, Aoun SM, et al. Predictors of complicated grief: a systematic review of empirical studies. Death Stud 2010; 34: 673-698.

26 McClain CS, Rosenfeld B, Breitbart W. Effect of spiritual well-being on end-of-life despair in terminally-ill cancer patients. Lancet 2003; 361: 1603-1607.

27 Berning JN, Poor AD, Buckley SM, et al. A novel picture guide to improve spiritual care and reduce anxiety in mechanically ventilated adults in the intensive care unit. Ann Am Thorac Soc 2016; 13: 1333-1342. 